\title{
Search Engine Optimization: What Drives Organic Traffic to Retail Sites?*
}

\author{
Michael R. Baye \\ Indiana University
}

\author{
Babur De los Santos \\ Indiana University
}

October 2013

\author{
Matthijs R. Wildenbeest \\ Indiana University
}

\begin{abstract}
The lion's share of retail traffic through search engines originates from organic (natural) rather than sponsored (paid) links. We use a dataset constructed from over 12,000 search terms and 2 million users to identify drivers of the organic clicks that the top 759 retailers received from search engines in August 2012. Our results are potentially important for search engine optimization (SEO). We find that a retailer's investments in factors such as the quality and brand awareness of its site increases organic clicks through both a direct and an indirect effect. The direct effect stems purely from consumer behavior: The higher the quality of an online retailer, the greater the number of consumers who click its link rather than a competitor in the list of organic results. The indirect effect stems from our finding that search engines tend to place higher quality sites in better positions, which results in additional clicks since consumers tend to click links in more favorable positions. We also find that consumers who are older, wealthier, conduct searches from work, use fewer words or include a brand name product in their search are more likely to click a retailer's organic link following a product search. Finally, the quality of a retailer's site appears to be especially important in attracting organic traffic from individuals with higher incomes. The beneficial direct and indirect effects of an online retailer's brand equity on organic clicks, coupled with the spillover effects on traffic through other online and traditional channels, leads us to conclude that investments in the quality and brand awareness of a site should be included as part of an SEO strategy.
\end{abstract}

Keywords: search engine optimization, organic clicks, search marketing

${ }^{*}$ Department of Business Economics and Public Policy, Kelley School of Business, Indiana University, Bloomington IN 47405; mbaye@indiana.edu, babur@indiana.edu, and mwildenb@indiana.edu. We thank Susan Kayser, Joowon Kim, and Yoo Jin Lee for research assistance. Funding for the data and research assistance related to this research was made possible by a grant from Google to Indiana University. The views expressed in this paper are those of the authors and do not necessarily reflect the views of Indiana University or Google. 


\section{Introduction}

Search engines are an important way of obtaining information on the internet. According to Alexa Traffic Rank, Google.com is the most popular website in the United States as well as in the world, and in May 2011, it was the first website to achieve one billion monthly unique visitors. ${ }^{1}$ Many people use search engines as a starting point for navigating the web, making search engines a crucial link in connecting content providers and users. This has spurred a sizable literature on search marketing that studies clicking behavior at search engines. To date, most of this literature has concentrated on the sponsored links that are typically displayed alongside organic links when consumers conduct searches.

While most of the economics and marketing literature on search engines has focused on paid clicks, the bulk of the traffic retailers receive through search engines is actually through unpaid clicks on organic links (Jerath, Ma, and Park, 2013). ${ }^{2}$ For this reason, more advertisers engage in search engine optimization to improve organic clicks than purchase sponsored links to get paid clicks (Berman and Katona, 2012). To the best of our knowledge, the present paper is the first to provide search marketers with information on drivers of organic clicks to aid in search engine optimization (SEO).

Existing studies of sponsored search are typically based on a modest number of search terms and the corresponding number of paid clicks received by a single retailer. Our research complements these studies by focusing on the organic clicks that 759 retail sites received from more than 12,000 search terms. There is considerable cross-sectional variation in our data: It includes sites operated by web-only as well as traditional retailers and covers 15 different retail segments including apparel, electronics, and mass merchants. For each of these search terms, we observe which retail sites received organic clicks as well as the number of clicks. We also obtained data from the first five pages of search results on Google and Bing for each search term, and this ultimately permits us to quantify the impact on organic clicks of a site's rank (position) in the search results. Our data also includes several different measures of the accumulated brand equity of online retailers. These data allow us to determine whether consumers are more likely to click the link of a retailer who is perceived to operate a high-quality site (as a result of the retailer's current and past investments

\footnotetext{
${ }^{1}$ Alexa Traffic Rank is calculated by combining a website's average number of daily visitors and page views over the past month.

${ }^{2}$ Our data are consistent with this finding.
} 
in advertising, the depth and breath of offerings, secure payments, one-click purchases, returns policies, and so on). Ultimately, this permits us to quantify the benefits of SEO strategies that attempt to gain traffic by improving a retailer's rank in organic search results, versus gaining traffic by improving the quality and brand awareness of a site.

Not surprisingly, we find that a retailer's rank on a results page is an important driver of its organic clicks: Exclusion from the first five pages of results for a search leads to a 90 percent reduction in organic clicks. For retailers that are listed on the first five pages of results, a one percent improvement in rank leads to 1.3 percent more organic clicks for that search.

Importantly, however, we also find that the brand equity of an online retailer is an important driver of organic clicks and that it is easy for search marketers to overlook the benefits of including investments in the quality and brand awareness of its site as part of an SEO strategy. The direct benefit of these and other investments in brand equity is an increase in the number of consumers clicking its link instead of a competing link on results pages. In addition, however, there is an indirect effect: Search engines tend to place retailers with greater brand equity in better positions, which results in additional increases in organic clicks. Finally, estimated effects of rank on organic clicks are keyword specific, while improvements in the brand equity of an online retailer increases clicks associated with all relevant searches. We find that, taking all of these effects into account, brand equity is as important as rank in determining organic clicks.

We also point out that investments that improve site quality and consumer awareness (and more broadly, that enhance an online retailer's brand equity) are likely to have spillover benefits in other channels that are not accounted for in this or other studies of organic and sponsored search. These benefits include increases in clicks through other online channels (such as price comparison sites), increases in the number of direct visits to a retailer's website, increases in visits through navigational searches at search engines, and increases in traffic at the retailer's physical stores. These considerations - coupled with the fact that position is a zero-sum game and thus a retailer is unlikely to obtain a sustainable advantage through direct efforts to improve its ranking - lead us to conclude that brand equity is one of the more important components of retailers' SEO strategies.

We also find that a retail site's brand equity is especially important in attracting organic traffic from individuals with higher incomes. Finally, our results indicate that consumers who are older, wealthier, conduct searches from work, use fewer words or include a brand-name product in their search are more likely to click a retailer's organic link following a product search.

The remainder of this section provides an overview of SEO and the related literature. Section 
2 discusses our data and describes the econometric methodology underlying our analysis. Section 3 presents our empirical findings, while Section 4 provides robustness checks and some additional results. Finally, we conclude in Section 5 with some additional managerial implications of our findings for SEO.

\section{$1.1 \quad$ Search Engine Optimization}

Figure 1 highlights the avenues that retailers have for gaining traffic through search engines. This screenshot shows the search results that appear following a search for "shoes online" on Google Search. In this particular example, three different types of links appear: top ads, side ads, and organic results. ${ }^{3}$ The top ads (marked by the red box in Figure 1), if any, are the highest listed search results and appear against a yellow background. For this particular search there are three top ads; the maximum number of top ads that are displayed is four. The organic results (marked by the blue box) are listed below the top ads. Up to ten organic results can appear on a search result page. Finally, the side ads (purple box) appear on the right-hand side of the screen; Google allows for up to eight side ads to be shown on a result page.

One way retailers obtain traffic is through the paid links that appear in top or side ads. Unlike organic links, retailers can directly influence the position of ads, which are displayed and ranked according to the results of an auction that is run in real time. Retailers identify keywords they want to bid on and specify how much they are willing to spend. Google determines the ad rank using a site's maximum bid specified for the keyword and a quality score, which includes factors like click-through rates and relevance. Advertisers only pay when the link is clicked; the cost per click is equal to the minimum amount needed to get a specific position (generalized second-price auction mechanism). There is an extensive literature (discussed below) examining this avenue for obtaining clicks.

A second way retailers obtain traffic through the search engine channel is through clicks on organic results, and this is the focus of our analysis. ${ }^{4}$ A site's position in Google's organic search results depends on the site's relevance to a given search term. The exact algorithm that Google uses to determine a site's ranking is proprietary; according to Google, it depends on thousands of

\footnotetext{
${ }^{3}$ Depending on the search term, up to four bottom ads may appear as well. For the search term "shoes online" no bottom ads were shown.

${ }^{4}$ Although our main focus is on organic (non-paid) links, we do take the presence of sponsored links (ads) into account, since they may affect organic clicking behavior.
} 
factors. $^{5}$

The ultimate goal of SEO is to optimize the organic traffic a retailer receives through product searches on search engines. One of the initial steps in any optimization process is identifying the benefits and costs of different strategies for increasing traffic. Our paper represents a first attempt to examine the benefits side of the ledger, and in particular, to quantify the drivers of retailers' organic clicks.

The first, and most common, SEO strategy is to tweak a site in an attempt to increase the rank of a retailer's organic link on the results pages for a given search term. The presumption is that higher ranks result in more organic clicks, but SEO requires quantifying the effects of rank on clicks. This is one objective of our paper.

One myopic tactic for improving position, known as a "black-hat" strategy, is designed to "trick" search engines into elevating a retailer's rank in the results. Search engines are themselves players, and have incentives to adapt algorithms to ensure that search engine users receive relevant results. Consumers are players too, and may favor links of retailers they know and trust: SEO strategies that focus exclusively on rank (such as spamming links or hiding keywords) might improve the position of a retailer's link but not impact its clicks. For this reason, SEO strategies based on "tricking" or "spamming" engines are unlikely to yield sustainable improvements in rankings, may not result in additional clicks, and can even backfire as a result of negative effects on reputation. Furthermore, it is important to recognize that rankings are effectively a zero-sum game: One retailer can move up on a particular results page only by pushing down the link of another retailer. Thus, while it makes sense for online retailers to ensure that their sites include page titles that accurately describe content, make use of head tags, are free of dead links, and so on, these efforts alone are unlikely to give a particular retailer a sustainable rank advantage because other retailers have incentives to engage in these strategies as well.

A second and more costly SEO strategy - but one that is more likely to yield sustainable improvements in a retailer's organic traffic from search engines - focuses on improving site quality and brand awareness, or more broadly on enhancing the online retailer's brand equity (which embodies current and past investments in advertising, service and return policies, depth and breath of offerings, prices, etc.). This strategy recognizes that consumers tend to click retailers that are more recognized, trusted, have reputations for providing value (in terms of prices, product depth or

\footnotetext{
${ }^{5}$ See http://www.google.com/explanation.html. One of these factors is Google PageRank, which is an algorithm that uses the number of incoming links to measure the relative importance of a website.
} 
breadth), service (well-designed websites, return policies, secure payment systems), and so on. This SEO strategy is alluded to by Google, which advises businesses to base “...optimization decisions first and foremost on what's best for the visitors of your site. They're the main consumers of your content and are using search engines to find your work. Focusing too hard on specific tweaks to gain ranking in the organic results of search engines may not deliver the desired results." 6

\subsection{Related Literature}

Our paper is connected to several different literatures, including a handful of academic papers on SEO which provide important theoretical insights into search engine optimization (Berman and Katona, 2012; Xing and Lin, 2006; and Sen, 2005). These papers highlight several features of the equilibrium interaction between websites and search engines that we take into account in our empirical analysis, including the endogeneity of the rank of organic links and the position of sponsored links in search results. To the best of our knowledge, there is no antecedent empirical research on SEO.

There is, however, a sizeable theoretical and empirical literature on search engines that focuses on the sponsored links that appear alongside the organic results. The theoretical literature has in particular focused on the auction mechanism behind these paid results (e.g., Edelman, Ostrovsky, and Schwarz, 2007; Varian, 2007). Earlier studies took user behavior as given; more recent work by Chen and He (2011) as well as Athey and Ellison (2012) take into account that users search optimally. White (2012) and Xu, Chen, and Whinston (2012) focus on trade-offs between organic and sponsored search results.

The empirical research on search engines has mostly focused on sponsored search as well. Yao and Mela (2011) develop a dynamic structural model of keyword advertising that takes optimal consumer behavior into account. Animesh, Ramachandran, and Viswanathan (2010) focus on quality uncertainty in sponsored search markets and find some evidence of adverse selection, but only for unregulated sponsored search markets. Ghose and Yang (2009) focus on ad placement and its effects on profitability and find a negative relationship between position and click-through rate as well as conversion rates. Agarwal, Hosanagar, and Smith (2011) also find a negative relationship between position and click-through rates but find a positive relationship with conversion rates, which means that the top position is not necessarily the most profitable.

\footnotetext{
${ }^{6}$ See Google's Search Engine Optimization Starter Guide, 2013, p. 2. A link to this guide is available online at http://support.google.com/webmasters/bin/answer.py?hl=en\&answer $=35291$
} 
Our paper is also related to three recent papers that focus on the relationship between sponsored and organic search results. Yang and Ghose (2010) find organic clicks to be positively related to the presence of sponsored links, and vice versa. However, the presence of an organic link increases the utility of a sponsored listing more than the other way around. Similarly, Agarwal, Hosanagar, and Smith (2012) find the presence of a link in the organic search results to be positively related to the click-through rate. However, they find the conversion rate to decrease. A third paper by Jerath, Ma, and Park (2013) uses clicks data based on 120 keywords to examine how the "popularity" of different keywords impacts clicking behavior. Their results suggest that less popular keywords are "more targetable" for sponsored search advertising than more popular keywords.

Our paper is related to a very large literature documenting the importance of screen position and a seller's reputation or brand equity ${ }^{7}$ for retailers selling through other online channels including price comparison sites, shopbots, and auction sites (Brynjolfsson and Smith, 2000; Melnik and Alm, 2002; Dellarocas, 2003; Baye and Morgan, 2009; Baye et al., 2009; and De los Santos, Hortaçsu, and Wildenbeest, 2012). While the broad message is that branding, screen position, consumer attributes, and retailer characteristics are all important determinants of click-through behavior in these channels, to date, little is known about their impact on organic clicks through search engines.

\section{Data Description and Econometric Model}

\subsection{Data Description}

Our main dataset is assembled using data from comScore Search Planner and contains information on the number of organic clicks websites received for search terms and phrases entered at main search engines (i.e., Google, Bing, Yahoo, AOL, and ASK) during August 2012. Search Planner uses the comScore panel, which contains all online browsing activity of around two million U.S. users. Since our goal is to analyze the drivers of organic traffic following product searches, we restrict our sample to only include websites that are internet retailers. For this we make use of Internet Retailer's Top 500 Guide, which contains a ranking of North America's 500 largest e-retailers based on annual web sales. Although not all of these retailers appeared in the comScore Search Planner database,

\footnotetext{
${ }^{7}$ Aaker (1991) defines brand equity as "a set of brand assets and liabilities linked to a brand, its name and symbol, that add to or subtract from the value provided by a product or service to a firm and/or to that firm's customers." Brand equity is based on factors like brand loyalty, name awareness, and quality. See Keller and Lehmann (2006) for a recent survey of the branding literature.
} 
some e-retailers (e.g., Amazon) operate multiple websites (e.g., Amazon.com and Zappos.com), resulting in a total of 759 retail sites for which we have click-through data. For each of these 759 retailers, we used Search Planner to identify all search terms that generated traffic from Google to the retailer. There is some overlap in search terms: as shown in Figure 1, Onlineshoes.com as well as Zappos.com appear relatively high in the organic results for the term "shoes online," which means that for both retailers this term is part of the set of search terms that generated traffic from Google. In total we end up with 12,184 distinct search terms that led users to the 759 online retailers. The third dataset we use contains all the links that appeared on the first five search results pages on Google Search and Bing Search for each of the 12,184 search phrases. We collected this data using a scraper written in Java; the data contains organic search results as well as paid links.

Not all 759 online retailers are relevant for each of the search terms in our data. For instance, Best Buy is not relevant for individuals searching for shoes and is therefore unlikely to show up in the search results for "shoes online." 8 Given that a retail site must be listed on the search results pages to receive organic clicks, we only include a retailer as an observation for a specific search term if we observe the retail site in our search results data. Since we only captured the first five pages of search results, this does not rule out that a site that did not appear in these search results did in fact get clicks; we therefore also include a retail site if the site received organic clicks for the search term according to the Search Planner database.

Our measure of a retail site's brand equity relies on the methodology developed in Baye, De los Santos, and Wildenbeest (2012). Briefly, this measure is based on navigational searches - that is, the number of organic clicks a particular retailer received from searchers who navigate to its site by including the retailer's name as a search term. Navigational searches include misspellings, and are essentially a shortcut for typing in the URL of a specific retailer and then searching its site; examples include "Amazon," "Amazn," and "Buy camera at Amazon." The idea is that sites with stronger brand names are better known to consumers and therefore, by a revealed preference argument, the number of navigational searches for a retailer at a point in time embodies all of its current and past efforts to improve the awareness of its brand through investments in advertising, service, depth and breath of offerings, website quality, and so on. Baye et al. provide evidence

\footnotetext{
${ }^{8}$ Indeed, Best Buy did not show up in at least the first 30 pages of search results on Google for the search term "shoes online" (checked on February 26, 2013).
} 
that this measure works well in both retail and education contexts. ${ }^{9}$ For example, they show that there is a strong relationship between navigational searches for universities and university rankings: Universities with stronger brands (e.g., Harvard University) receive significantly more navigational searches than universities with weaker brands (e.g., Indiana University).

While we use navigational searches to construct our measure of brand equity, our dependent variable excludes organic clicks from navigational searches. We seek to understand why searchers choose to click on Amazon (or some other link) following a non-navigational search like "Levis Jeans," and not why they click on an Amazon link following a navigational search like "Amazon." Thus, in our econometric analysis of organic clicks, we exclude all search terms (and hence organic clicks based on searches) containing the name of one of the 759 retail sites. This results in 40,117 observations, where each observation is the number of clicks for each search term-retailer.

In addition to the number of organic clicks per retail site, the Search Planner data also contains information on the demographics of searchers using each of the search terms, including the percentage of searchers by age, income, and location (home or work). We also used data from Internet Retailer's Top 500 Guide to identify each retailer's retail segment (e.g., mass merchant, apparel and accessories, sporting goods, etc.), whether the retailer has a presence on social media (Facebook or Twitter), the year in which the retail site began operating online, and whether the retailer has a brick-and-mortar presence. Table 1 provides summary statistics of these variables, as well as the other variables we use in our analysis.

Finally, we analyzed each search term and constructed search-term specific variables based on the content of the search term. The first variable is the number of words in the search term. The second variable, denoted branded search term, is an indicator variable for whether the search terms include the brand name of a product (e.g., Nike or Adidas) in the product search. Note that, in our sample, this is different than the brand associated with a particular retailer's site (e.g., Zappos or Amazon). These two search-term specific variables may tell us something about the intent of search. For instance, an individual searching for "Nike running shoes" is more specific in what she is looking for than someone searching for "shoes online," and this may affect clicking behavior.

\footnotetext{
${ }^{9}$ Although many of the general branding principles carry over to retailers, the measurement of retail brand equity provides some unique challenges; Ailawadi and Keller (2004) identify some unique issues to the measurement of retail brand equity. For our purposes, the key is that this measure is related to the overall image of an online retailer and its attributes, which includes factors like name recognition, product breadth and depth, shopping experience, and reputation (prices, quality, shipping, returns policy, etc.).
} 


\subsection{Econometric Model}

Our main objective is to study the drivers of organic clicks arising from searches for products on search engines. Let Clicks $_{i k}$ denote the total number of organic clicks retailer $i$ received from individuals searching for search term $k$. Because of the presence of substantial positive skewness in organic clicks data, we use a log-normal regression model to analyze the relationship between organic clicks and the explanatory variables, i.e.,

$$
\ln \left(\text { Clicks }_{i k}\right)=\gamma_{0}+\gamma_{1}\left(R N O_{i k}\right)+\gamma_{2} \ln \left(\text { Rank }_{i k}\right)+\gamma_{3} \text { Sponsored }_{i k}+\gamma_{4} \ln \left(\text { BE }_{i}\right)+\gamma_{5} X_{i j}+\varepsilon_{i j}
$$

where $R N O_{i k}$ (short for rank not observed) is a dummy variable that equals 1 if retailer $i$ is not observed on the first five pages of search results for search term $k, \operatorname{Rank}_{i k}$ is the rank (or position) of retailer $i$ on the first five pages of search results for search term $k$, Sponsored $_{i k}$ is a dummy for whether the retailer had a sponsored link on the first results page for search term $k, B E_{i}$ a measure of retailer $i$ 's brand equity, and $X_{i j}$ is a vector of other other controls including demographic variables, search term specific variables, retailer characteristics as well as retail segment fixed effects.

There are two primary concerns with estimating this equation: (i) it is likely that some of the explanatory variables are endogenous (correlated with $\varepsilon_{i j}$ ); and (ii) owing to the nature of the Search Planner data, we only observe the dependent variable in equation (1) when clicks exceed a certain threshold. Below we discuss how we deal with these concerns.

\subsubsection{Endogeneity}

Google continuously updates its rankings of search results to generate the most relevant search results, which means that our rank variable will depend on past clicks. It is therefore likely that rank is correlated with the error term and thus endogenous. A similar effect may be at work for the ads variable: Ad positions are based on the outcome of a second-price auction that takes the relevance of the bidder with respect to the search term into account, again making it likely that ad positions are based on past clicking behavior on Google.

The standard approach in the literature on clicks at platforms (e.g., clicks at price comparison sites or sponsored clicks at search engines) is to assume that such positions are exogenous. Using the Wu-Hausman test for endogeneity, however, we reject the hypothesis that rank and ad positions are exogenous in our data $(\mathrm{p}=0.0023$ and $\mathrm{p}=0.0116$, respectively). To account for the potential endogeneity of these variables, we use information about rank and ads on Bing as instruments. 
These instruments are correlated with the endogenous regressors, but are unlikely to be correlated with the error term, since Bing's decisions on search result rankings and ad positions are not based on past clicks on Google. Indeed, using the Sargan test for overidentifying restrictions, we cannot reject the hypothesis that these are valid instruments $(\mathrm{p}=0.3795)$.

One might also worry that our measure of brand equity is correlated with the error in equation (1). Based on the Wu-Hausman test, however, we cannot reject the hypothesis that our measure of brand equity is exogenous, even at high significance levels $(\mathrm{p}=0.9598)$. Our main results thus treat only position and ads as endogenous. Section 4 shows that our results are robust to the use of three alternative measures of brand equity that are also unlikely to be correlated with the errors.

\subsubsection{Sample Selection}

As we explained in Section 2.1, a retail site is included as an observation if it appears on the first five pages of the Google search result page for a specific search term, independent of whether the retailer received organic clicks according to Search Planner. Complicating matters, Search Planner only reports the number of organic clicks if those clicks exceed a certain threshold, which means we do not know whether sites receiving zero organic clicks according to Search Planner really received no click-throughs for the search term in question or whether they were censored.

What makes our setting different from a standard censoring environment is that the selection rule depends on total clicks (including paid clicks) rather than just organic clicks. This means that a different probability mechanism generates both the zero clicks and the positive clicks, and this cannot be captured by a standard Tobit censoring model. For this reason, we estimate a Heckmantype selection model. As we argued in the previous subsection, endogeneity is likely to be important in our data, so we allow for endogenous explanatory variables. Estimation of the model consists of two stages. In the first stage we regress a dummy for having positive clicks on all exogenous variables (including instruments) $z$. Here, it is important to include at least one more instrument than is necessary for dealing with the endogeneity problem (otherwise identification is purely based on the parametric form of the inverse Mills ratio). This additional exclusion restriction should relate to the probability of observing positive organic clicks. Since this probability relates to the number of total clicks, we use additional variables in the selection equation that are important for getting paid clicks: We add dummies for whether a sponsored link was displayed on each of pages 2 through 5 in the Bing search results. We obtain the inverse Mills ratio, given by $\hat{\lambda}=\lambda(z \hat{\delta})=\phi(z \hat{\delta}) / \Phi(z \hat{\delta})$ 
from the selection equation, and add this to the second stage to obtain

$$
\ln \left(\text { Clicks }_{i k}\right)=\gamma_{0}+\gamma_{1}\left(\text { RNO }_{i k}\right)+\gamma_{2} \ln \left(\text { Rank }_{i k}\right)+\gamma_{3} \text { Sponsored }_{i k}+\gamma_{4} \ln \left(\text { BE }_{i}\right)+\gamma_{5} X_{i k}+\gamma_{6} \hat{\lambda}+\varepsilon_{i k}
$$

We estimate this equation using the selected subsample (for which we observe organic clicks), i.e.,by

two-stage least squares using instruments $(z, \hat{\lambda})$ for the endogenous variables $R N O_{i k}, R_{a n k} k_{i k}$ and Sponsored ik $_{\text {. }}$

\section{Results}

Table 2 provides results for the specification in equation (2), which regresses the logarithm of organic clicks on explanatory variables that account for the impact on clicks of rank, brand equity, retailer characteristics, as well as characteristics including searcher demographics and the nature of search terms. Recall that these results control for potential endogeneity as well as censoring, and include a constant and retail segment fixed effects to account for potential differences in clicks across the 15 retail segments identified in Table 1. All statistical tests are based on the reported robust standard errors, which account for potential heteroskedacity.

The estimated coefficient for the inverse Mill's ratio is significantly different from zero at the one percent level, which indicates that it is indeed appropriate to control for censoring of the data. We discuss the other estimated parameters of the model below.

\subsection{Rank}

As discussed earlier, one potential goal of SEO is to increase the ranking (or position) of a retailer's links in organic search results. But just how important is position in driving a retailer's organic clicks following a product search? The first two estimated coefficients in Table 2 provide an answer. The estimated coefficient for rank not observed captures the effect of a retailer's link not being included on the first five pages of search results for a given search term. The estimated coefficient of -2.335 is significant in both an economic and statistical sense, and implies that a firm not appearing on the first five pages receives 90 percent fewer clicks for a given search term. For a retailer whose link is observed on the first 5 pages, the estimated coefficient of -1.347 for $\ln (\operatorname{Rank})$ implies that a 1 percent decline in rank induces a 1.3 percent reduction in organic clicks for a given search term. For example, a retailer moving from the fifth to the sixth position in a search for 
"jeans" experiences a 27 percent reduction in organic clicks for that search term, while moving from the sixth to the seventh position results in a 22 percent decline. ${ }^{10}$

While these results indicate that rank is a very important driver of organic clicks following product searches, it is important to stress that the unit of observation underlying these results is $\operatorname{Rank}_{i, k}$; that is, retailer $i$ 's position in the results for search term $k$. Thus, these rank coefficients measure the effect of improving a retailer's position for a single search term. Consequently, SEO efforts that are term specific (e.g., designed to elevate a retailer's rank following a search for "jeans" but that have no effect on positions following other product searches), will result in a much smaller percentage improvement in that retailer's total organic clicks. By way of example, the average retailer in our sample was relevant for about 60 search terms, so the corresponding effect on total organic clicks is about 1/60th of the rank coefficients in Table 2. For example, the estimated coefficient of -1.347 for $\ln ($ Rank $)$ implies that a 1 percent improvement in rank following a given keyword search results in a $0.02(=1.347 / 60)$ percent increase in total organic clicks.

These results indicate that the returns to term-specific SEO critically depend on the breadth and depth of a retailer's product offerings and hence the number of search terms in which its link is relevant.

\subsection{Retailer Brand Equity}

Table 2 also reports estimates of the direct effect of a retailer's brand equity on the clicks it receives following a product search. The estimated coefficient for the logarithm of brand equity is positive and very precisely estimated, indicating that the direct effect of brand equity of a retailer's site is an important determinant of the organic clicks it receives following a product search. It is important to note that, unlike rank, brand equity is not search-term specific. As such, the estimated impact of brand equity in Table 2 captures the impact on a retailer's total organic clicks: Holding rank and the other factors influencing clicks constant, a one percent increase in a site's brand equity results in a 0.084 percent increase in a retailer's total organic clicks. These results, coupled with those discussed above for rank, indicate that a marginal improvement in a retailer's brand equity has a larger direct effect on its organic clicks than SEO efforts resulting in a marginal improvement in its position associated with a particular search term.

\footnotetext{
${ }^{10}$ We also ran specifications with position bins rather than the log-linear specification and the results were qualitatively similar.
} 
Notice that the estimated coefficient for brand equity in Table 2, which corresponds to $\gamma_{4}$ in equation (2), measures the direct effect of retailer $i$ 's brand equity on its organic clicks. However, because search engines' algorithms determine rankings or positions of listings, in part, on past clicking behavior, there is also an indirect effect of brand equity on clicks: Retailers with greater brand equity and stronger brand names enjoy more clicks, which results in better future ranks. Figure 2, which graphs the average number of times retail sites appear on the first page of search results for different sextiles of brand equity, shows that online retailers with stronger brands in our data tend to have better ranks on results pages following non-navigational searches. The total effect of brand equity on clicks includes the direct effect identified in Table 2 as well as the indirect effect through rank.

To identify the total effect of brand equity on clicks, we use a standard two-step procedure (Alwin and Hauser, 1975). In a first step we regress the rank variables on the logarithm of brand equity to obtain brand-equity adjusted ranks to determine the impact of brand equity on rank. In the second step, we proceed as in equation (2) but using these brand equity adjusted ranks. This estimated regression yields an estimate of the total effect of brand equity on organic clicks, including both the direct effect shown in Table 2 as well as the indirect effect stemming from the impact of brand equity on position. As shown in Figure 3, the indirect effect of brand equity on clicks (through its impact on rank) is slightly larger than the direct effect, resulting in a total effect on organic clicks of 0.185 - roughly twice the direct effect. ${ }^{11}$

From the standpoint of SEO, these results highlight an important interaction between brand equity and rank. A one percent improvement in a retailer's brand equity directly increases its total organic clicks by 0.084 percent, owing to the fact that consumers more frequently click on its link instead of a competing one in the list of search results. Ultimately, this induces search engines to elevate the firm's position in all relevant searches, which results in an additional 0.101 percent increase in clicks. The total effect of a one percent improvement in a retailer's brand equity is therefore a 0.185 increase in total organic clicks. Unlike the impact of rank, this percentage increase applies to a retailer's overall clicks rather than the clicks stemming from a single search phrase. Thus, there are signficant benefits (in terms of organic clicks) to SEO efforts that improve the quality and awareness of a retailer's site.

\footnotetext{
${ }^{11}$ Note that this procedure does not impact any of the other parameter estimates in Table 2, nor does it impact the overall fit of the model. The estimated total effect is signficant at the 1 percent level; the robust standard error for the point estimate of 0.185 is 0.047 .
} 


\subsection{Consumer Characteristics}

The specification in Table 2 indicates that consumer characteristics systematically influence organic clicks on search engines. These results are of potential interest to retailers engaging in SEO to attract customers within particular demographic groups.

Notice that all of the income categories are statistically significant at the 5 percent or better levels: Consumers with higher incomes tend to more frequently click an organic link following a product search than do consumers with lower incomes. While not all of the age categories are

statistically significant, the general pattern suggests that younger individuals are less likely to click organic links than older individuals. Interestingly, the results also indicate that consumers searching from home are less likely to click following an organic search than individuals conducting a product search from the workplace. These patterns may stem from differences in search behavior across consumers with different demographic characteristics. For example, consumers with greater incomes may be more likely to conduct product searches on platforms such as Amazon rather than a search engine; individuals with lower incomes may be more likely to search using price comparison sites.

\subsection{Keyword-Specific Effects}

One might worry that the demographic effects documented above stem from differences in the sophistication of searchers with different demographic characteristics. To account for this, we include two controls for the nature of the keyword search: (1) branded search term, which is an indicator for whether the search phrase includes a brand-name product (e.g., "Levis Jeans"), and (2) number of words, which is simply a count of the number of words included in the search. The results indicate that searchers who include specific brands of products in their terms, or who use fewer words in their search, are more likely to click an organic link following a product search. These findings are consistent with Yang and Ghose (2010), who find a positive relationship between branded searches and paid clicks as well as a positive relationship between keyword length and paid clicks. Our results are consistent with longer search phrases resulting in organic results that contain less relevant links, which would result in fewer organic clicks but more paid clicks. 


\subsection{Other Retailer Characteristics}

In addition to retail segment fixed effects, the results in Table 2 include controls for other retailer characteristics that might impact SEO. We discuss each of these in turn.

First, note that retailers with a sponsored link on the first page of organic results receive 37 percent more organic clicks after controlling for rank, brand equity, and other drivers of clicks. This positive relationship is consistent with findings of Yang and Ghose (2010) and suggests that these sponsored links may provide searchers information about the retailer that increases the perceived value of clicking its organic link. For instance, such a link might lead searchers to conclude that the corresponding organic listing is relevant; alternatively, the sponsored link might have value as an advertisement that increases the brand equity of the retailer, making consumers more likely to click on organic as well as sponsored links. As with rank effects, however, Ads is a keyword specific variable so this 37 percent increase applies to the base of clicks from that keyword; it does not imply a 37 percent increase in overall organic clicks.

Second, the results in Table 2 indicate that web-only retailers receive about 13 percent more total organic clicks than their bricks-and-clicks counterparts. This highlights that drivers of organic clicks through search engines may differ from those through other channels, such as price comparison sites. For example, Baye et. al (2009) find that bricks-and-clicks retailers selling on a leading price comparison site receive over 25 percent more clicks than their web-only counterparts.

Finally, notice that the specification in Table 2 includes additional controls designed to capture potential drivers of clicks that are not accounted for in the specification. These include site age (a potential proxy for cumulative brand equity) and whether the site has a presence on social networks (Facebook and Twitter). While the coefficients for these two controls have a positive effect on organic clicks, they are relatively small and not statistically significant at conventional levels. On balance, we view this as evidence that the effects discussed above are not the result of spurious correlation with excluded drivers of organic clicks.

\section{Robustness Checks and Additional Results}

In this section we demonstrate that our results are robust to a variety of alternative specifications, and offer some additional results that are of potential interest for SEO related to generating traffic from consumers in different income classes. 


\subsection{Results Based on Alternative Measures of Retailer Brand Equity}

Recall that the Wu-Hausman test did not trigger any formal concerns about our measure of brand equity being correlated with the error in equation (2). Nonetheless, one might worry that such tests never "prove" exogeneity or wonder whether our results are sensitive to this particular measure of brand equity. Table 3 shows that our main findings are robust to using three alternative measures of brand equity.

The first specification in Table 3 uses navigational searches on Google from July rather than August to construct the measure of retailer brand equity. Since navigational searches in July were predetermined at the time searchers made their August click decisions, this lagged measure of brand equity mitigates concerns that an unobserved factor drives both navigational and nonnavigational clicks in the August clicks data. As shown in column (1), all parameter estimates, including the brand equity coefficient, increase slightly in magnitude but are qualitatively similar to those reported in Table 2.

The second specification in Table 3 uses navigational searches from Bing rather than Google to measure brand equity. Since Bing has a different population of users and employs a different algorithm for returning search results, it is unlikely that unobserved factors that affect clicks on Google are correlated with this measure of brand equity based on navigational searches on Bing. The results in column (2) show that our findings are robust to using this alternative measure of brand equity.

The final specification in Table 3 is based on an alternative measure of brand equity pioneered by Animesh, Ramachandran, and Viswanathan (2010). This measure is constructed from data produced by the web traffic reporting firm, Alexa, and measures the "Sites Linking In from Alexa." It is based on the number of links to a website from sites that are visited by individuals on Alexa's web traffic panel. ${ }^{12}$ Animesh, Ramachandran, and Viswanathan use these data to measure seller quality, noting that links pointing to a website can be viewed as a positive recommendation from the referring site. As shown in column (3) of Table 3, our results are also robust to using this alternative measure of brand equity — as well as to interpreting the brand equity effect identified in our earlier results as purely capturing "seller quality."

\footnotetext{
${ }^{12}$ According to Alexa.com, "Links that were not seen by users in the Alexa traffic panel are not counted. Multiple links from the same site are only counted once." See also Alexa.com.
} 


\subsection{Alternative Censoring Models}

Table 4 shows that our main results are robust to using a Tobit censoring model rather than the Heckman selection model used in our main specification. The Tobit model can be interpreted as a constrained version of the selection model, with the selection and outcome equations being equivalent while not allowing for any selection bias. Column (1) reports results controlling for both selection and endogeneity, as in our main specification, while column (2) simply controls for selection. Comparing the parameter estimates to those in column (1) of Table 2, most parameters increase in magnitude and are largely consistent with those reported in our main specification in Table 2.

\subsection{Brand Equity and Consumer Income}

Our main specification in Table 2 assumes that the coefficients for the drivers of organic clicks are identical across consumers in different income groups. We conclude by showing that our qualitative results are not an artifact of pooling across searchers with different incomes. ${ }^{13}$ These results are potentially of independent interest, since different retailers may use SEO to target consumers in different income groups.

Table 5 reports the results of estimation by income group, and shows that our main qualitative findings hold in the absence of pooling. Interestingly, however, these results suggest that brand equity has differential effects across individuals in different income classes.

For the three lowest income groups, the elasticity of organic clicks with respect to brand equity is smaller than the 0.084 reported in Table 2 based on pooled data, while that for the top two income groups is greater. Although one of the brand equity coefficients is not estimated precisely enough to infer that it is significantly different from the excluded ( $\$ 51$ to $\$ 74$ thousand income) category, the results on balance indicate that brand equity is a more important driver of organic clicks for richer than poorer searchers. This result is illustrated in Figure 4, where the dots represent the point estimates for the elasticity of organic clicks with respect to brand equity for the five income groups, and the lines represent the corresponding $95 \%$ confidence intervals.

\footnotetext{
${ }^{13}$ We also ran specifications that did not pool across searchers of different ages or conducting searches from different locations, but those results did not materially differ from those presented in Table 2 .
} 


\section{Managerial Implications for SEO}

Our results are intuitive: When confronted with a list of potentially "relevant" search results, consumers are more likely to click the link of the retailer with the greatest brand equity. That is, holding other drivers of clicks constant, consumers tend to click retailers that are more recognized, trusted, have reputations for providing value (in terms of prices, product depth or breadth), service (well-designed websites, return policies, secure payment systems), and so on. Unlike price comparison sites and other online channels where signals of these attributes may be separately observed (through displays that include user feedback ratings, third-party certification, prices, shipping costs, etc.), the only signals consumers observe in organic product search results are sites' names (which embody their brand equity) and their "relevance" (as proxied by the rank or position that the search engine's algorithm assigns each organic link). We also showed that our findings are robust to several alternative specifications and, importantly, to controls for censoring as well as the en-

dogeneity of a retailer's rank or position in the list of organic results. We conclude by discussing implications of our analysis for search engine optimization, and by providing a few caveats regarding their implementation.

\subsection{Rank or Position on Results Pages}

Our results indicate that rank is an important determinant of clicks; it is hard for a retailer to get organic clicks from a specific product search if its link is not observed on the first five pages of results for that search. For retailer's above this virtual "fold," the elasticity of clicks with respect to rank is about unity: a one percent improvement in rank leads to a one percent increase in organic clicks (for that search). Our results thus suggest that there are returns to SEO efforts that make it easier for search engines to determine a site's relevance for a particular product search. This includes making effective use of anchor texts, descriptive headings and meta tags, robot.txt files, and using accurate and unique page titles.

However, while these sorts of strategies for SEO are necessary and important, our analysis suggests that it would be a mistake to make them the exclusive focus of SEO. Rankings are a zero-sum game, and other retailers also have strong incentives to ensure that their sites contain the information needed to be properly indexed by search engines. In light of best responses by other sites, these efforts may prevent a retailer from losing ranks due to miscommunication with search engines, but are unlikely to result in improvements in the equilibrium ranks of a particular retailer's 
link. Additionally, strategies designed to improve rank need not result in a long-run increase in organic clicks. This is particularly true of efforts to "trick" search engines into viewing a site to be relevant when it is not.

It is also important for managers to recognize that estimates of the impact of rank on organic clicks are keyword specific, and that apples-to-apples comparisons of the benefits of rank verses other drivers of clicks requires an adjustment for the importance of that search in generating organic clicks relative to all relevant searches. Among other things, this means that the returns to focusing on improving rank may be larger for a niche retailer (which sells a single product on a site with a single page) than a mass merchant with thousands of products and pages.

\section{$5.2 \quad$ Site Branding}

The benefits of including brand equity as part of an SEO strategy are high. Such investments include increasing consumer awareness (through traditional as well as online advertising), making the site more user-friendly (easier to navigate), providing quality content and service (such as one-click purchases, easy return policies, and using a secure payment system), and more generally, enhancing the value of the brand that underlies the retailer's link. A number of retailers - including both Amazon and Walmart-have successfully used these strategies.

Investments in branding have both direct and indirect effects on organic clicks. The direct effect stems from our finding that consumers are more likely to click on links they know and trust - a finding that is consistent with evidence from other channels, including price comparison and auction sites. But brand equity has an equally sizeable indirect effect: Search engines want to provide users with relevant links, and the brand equity of a site is correlated with the relevance of links, which leads to better ranks and positions. Importantly, the brand equity of a site impacts organic clicks for all relevant keywords, not just those related to a particular search, so there is an amplification effect of SEO strategies targeted to improve the branding of a site.

In addition to spillovers on organic clicks related to searches for other keywords, investments that enhance brand equity are likely to lead to benefits in other channels. These benefits are not accounted for in our estimates, nor in the benefits that other papers document regarding the impact of brand and reputation on sponsored clicks. For example, our analysis focuses exclusively on drivers of non-navigational searches at search engines, so the regression coefficients in Table 2 do not include the benefits of increases in brand awareness or site quality on organic traffic from navigational searches at search engines. Likewise, improvements in a site's brand equity are likely 
to result in more direct visits to a retailer's site, as well as more clicks at other platforms including price comparison and auction sites. Finally, for retailers operating both online and physical stores, some investments (such as advertising) may result in positive spillovers into the physical channel.

Our analysis indicates not only that investments in brand equity lead to significantly more organic clicks, but that these investments are more likely to be sustainable than SEO efforts focused entirely on rank. Additionally, such investments have spillover benefits in other channels as well, as has already been documented in extensive research on other online markets as well as traditional retail channels. For all of these reasons, we conclude that site quality, brand awareness, and other investments that enhance the brand equity of an online retailer are important components of an overall SEO strategy.

\subsection{Search Term Considerations}

Some search terms and phrases are more likely to generate clicks than other keywords, even when one accounts for differences in the brand equity of different retailers and their ranks in search results. This is potentially relevant for SEO as well. For example, our finding that searchers including the specific brand of a product (e.g., "Levis Jeans") in a search are more likely to click an organic link suggests that retailers selling branded products benefit by ensuring that their sites present information about the brands in their portfolio in a way that allows search engines to properly index them. Likewise, searchers using longer keywords are less likely to click an organic link, so parsimony in this regard is also important for SEO.

\subsection{Demographic Considerations}

Our findings that individuals that are older, have higher incomes, or who conduct product searches at work are more likely to click organic links also have ramifications for SEO. Among other things, these results suggest that SEO is more likely to be important for retailers targeting consumers with these demographic characteristics. In addition, since the elasticity of organic clicks with respect to brand equity is higher for individuals with higher incomes, the marginal benefits of SEO efforts targeted at improving the quality and brand awareness of a site are greater for retailers targeting individuals with higher incomes. More generally, the key implication is that the benefits of SEO vary, depending on the demographic characteristics of the consumers retailers are attempting to attract through this channel. 


\subsection{Retailer Considerations}

The relationship between sponsored links and organic clicks identified in our data highlights yet another set of spillovers that complicates the calculus of SEO. Retailers attempting to increase traffic through organic links should recognize that there are possible spillovers from paid links: Consumers are more likely to click organic links associated with sponsored links. On the surface, this might seem like a pure win for retailers, since a sponsored link that results in an organic click rather than a paid click costs nothing. This is unlikely to be part of a sustainable strategy, however. Ultimately, if consumers click a retailer's organic rather than sponsored link, its prospects for winning that sponsored link in an auction will decline, since search engines have little incentive to allocate scarce ad space to retailers that do not receive sponsored clicks.

\subsection{Concluding Caveats}

Our analysis has focused on the potential benefits of SEO by focusing exclusively on the drivers of organic clicks. We have not taken into account the costs of improving these drivers, such as the costs of improving the meta tags associated with a particular keyword to improve rankings or advertising through traditional media to improve the brand awareness of a site. Costs are obviously an important component of optimization, and it would be a mistake to base SEO decisions purely on the drivers documented above. Future research documenting the costs of different SEO strategies is therefore also important for the SEO literature.

It is also important to recognize that search engines are only one of many online platforms where consumers conduct product searches. Baye et al. (2013) note that, in June 2012, consumers using browsers conducted 634 million product searches at retailer sites (such as Walmart.com), 134 million product searches at price comparison sites (such as Dealtime.com), and 877 million searches at marketplace sites (such as eBay.com). They also point out that $70 \%$ percent of eBay's listings were for new products, and over $60 \%$ percent of its listings were through posted prices rather than auctions. Unlike SEO efforts designed to improve rankings at a search engine, SEO efforts to improve a retailer's brand equity can improve the clicks it receives from searches in these other channels. Since these spillover benefits are difficult to quantify, it is easy for those engaging in SEO to underestimate the benefits of investing in the quality and brand awareness of a site. 


\section{References}

[1] Aaker, David A. (1991). "Managing Brand Equity: Capitalizing on the Value of a Brand Name." The Free Press, New York, NY.

[2] Agarwal, Ashish, Kartik Hosanagar, and Michael D. Smith (2011). "Location, Location, Location: An Analysis of Profitability of Position in Online Advertising Markets." Journal of Marketing Research, 48 (6), pp. 1057-1073.

[3] Agarwal, Ashish, Kartik Hosanagar, and Michael D. Smith (2012). "Sponsored Search: Do Organic Results Help or Hurt the Performance and under what Conditions?" Working Paper.

[4] Ailawadi, Kusum L. and Kevin Lane Keller (2004). "Understanding Retail Branding: Conceptual Insights and Research Priorities." Journal of Retailing, 80 (4), pp. 331-342.

[5] Alwin, Duane and Robert M. Hauser (1975). "The Decomposition of Effects in Path Analysis." American Sociological Review 40, pp. 37-47.

[6] Animesh, Animesh, Vandana Ramachandran, and Siva Viswanathan (2010). "Quality Uncertainty and the Performance of Online Sponsored Search Markets: An Empirical Investigation.” Information Systems Research, 21 (1), pp. 190-201.

[7] Athey, Susan and Glenn Ellison (2011). "Position Auction with Consumer Search." The Quarterly Journal of Economics, 126 (3), 1213-1270.

[8] Baye, Michael R., Babur De los Santos, and Matthijs R. Wildenbeest (2012). "What's in a Name? Measuring Prominence, and its Impact on Organic Traffic from Search Engines." Kelley School of Business BEPP 2012-09 Working Paper.

[9] Baye, Michael R., Babur De los Santos, and Matthijs R. Wildenbeest (2013). "The Evolution of Product Search," Journal of Law and Economic Policy 9, pp. 201-221.

[10] Baye, Michael R. and John Morgan (2009). "Brand and Price Advertising in Online Markets." Management Science 55 (7), pp. 1139-1151.

[11] Baye, Michael R., J. Rupert J. Gatti, Paul Kattuman, and John Morgan (2009). "Clicks, Discontinuities, and Firm Demand Online," Journal of Economics 83 Management Strategy, 18, pp. $935-975$. 
[12] Berman, Ron and Zsot Katona (2012). "The Role of Search Engine Optimization in Search Marketing." Hass School of Business Working Paper.

[13] Brynjolfsson, Erik and Michael D. Smith (2000). "Frictionless Commerce? A Comparison of Internet and Conventional Retailers." Management Science, 46 (4), pp. 563-585.

[14] Chen, Yongmin and Chuan He (2011). "Paid Placement: Advertising and Search on the Internet." The Economic Journal, 121 (556), pp. F309-F328.

[15] Dellarocas, Chrysanthos (2003). "The Digitization of Word of Mouth: Promise and Challenges of Online Feedback Mechanisms." Management Science 49 (10), pp. 1407-1424.

[16] De los Santos, Babur, Ali Hortaçsu, and Matthijs R. Wildenbeest (2012). "Testing Model of Consumer Search Using Data on Web Browsing and Purchasing Behavior." American Economic Review, 102 (6), pp. 2955-2980.

[17] Edelman, Benjamin, Michael Ostrovsky, and Michael Schwarz (2007). "Internet Advertising and the Generalized Second-Price Auction: Selling Billions of Dollars Worth of Keywords." American Economic Review, 97 (1), pp. 242-259.

[18] Ghose, Anindya and Sha Yang (2009). "An Empirical Analysis of Search Engine Advertising: Sponsored Search in Electronic Markets.” Management Science, 55 (10), pp. 1605-1622.

[19] Goldfarb, Avi, Qiang Lu, and Shridhar Moorthy (2009). "Measuring Brand Value in an Equilibrium Framework." Management Science 28 (1), pp. 69-86.

[20] Jerath, Kinshuk, Liye Ma, and Youn-Hoon Park (2013). "Consumer Click Behavior at a Search Engine: The Role of Keyword Popularity." Working Paper.

[21] Keller, Kevin L. and Donald R. Lehmann (2006). "Brands and Branding: Research Findings and Future Priorities." Marketing Science 25 (6), pp. 740-759.

[22] Melnik, Mikhail I. and James Alm (2002). "Does a Seller's eCommerce Reputation Matter? Evidence from eBay Auctions." The Journal of Industrial Economics 50 (3), pp. 337-349.

[23] Smith, Michael D. and Brynjolfsson, Eric (2001). "Consumer Decision-Making at an Internet Shopbot: Brand Still Matters." The Journal of Industrial Economics 49 (4), pp. 541-558. 
[24] Varian, Hal (2007). "Position Auctions." The Journal of Industrial Economics 25 (6), pp. $1163-1178$.

[25] White, Alexander (2012). "Search Engines: Left Side Quality versus Right Side Profits." Working Paper.

[26] Yang, Sha and Anindya Ghose (2010). "Analyzing the Relationship Between Organic and Sponsored Search Advertising: Positive, Negative, or Zero Interdependence?" Marketing Science 29 (4), pp. 602-623.

[27] Yao, Song and Carl F. Mela (2011). "A Dynamic Model of Sponsored Search Advertising." Marketing Science 30 (3), pp. 447-468.

[28] Xu, Lizhen, Jianqing Chen, and Andrew Whinston (2012). "Interplay Between Organic Listing and Sponsored Bidding in Search Advertising." Working Paper. 
Figure 1: Search Results

Search Images Videos Maps News Shopping Gmail More $\mathbf{T}$

shoes online

Search About $412,000,000$ results

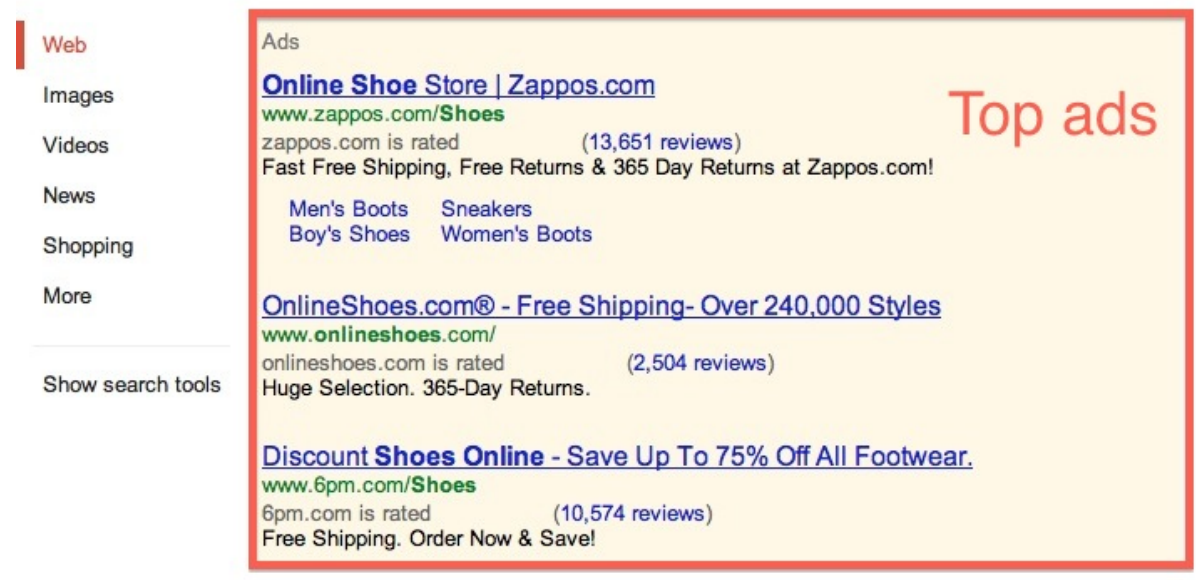

Shoes, Boots, Sandals - Free Shipping, Easy Returns on All Shoes ... www.shoes.com/ - Cached - Similar

Shop online at shoes.com for a great selection of shoes, boots and sandals for boys, girls, women and men with FREE SHIPPING on all orders.

Women's - Men's - Kids - Girls

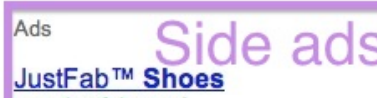

JustFat

www.justfab.com/

New Shoes In All Styles \& Sizes.

Get 1st Item Under \$20. Today Only!

\section{ShoesXL@ Official Site}

www.shoesxl.com

Get $\$ 25$ Off \$75, Use Code LORO.

Men's Shoes Up to Size 18!

\section{TOMS One for One Shoes}

www.toms.com/

With Every Pair You Purchase,

TOMS Will Give a Pair to a Child

Cheap Women's Shoes

www.shiekhshoes.com/Women_Shoes

shiekhshoes.com is rated

Big Sale On Brand Name Shoes.

Great Brands \& Prices!

Womens Shoes

www.shoedazzle.com/

Buy 1, Get 1 Free Sale. Stock your

closet during our 2 -for- 1 event.

Shoes, Clothing, and More | Zappos.com

www.zappos.com/ - Cached - Similar

Zappos.com was founded in 1999 with the goal of becoming the premiere destination for

online shoes. Since then, we've become much more than just an online ...

Men's, Women's \& Kids' Shoes and Footwear at OnlineShoes.com

www.onlineshoes.com/ - Cached - Similar

Free Shipping, 365-Day Returns. 24/7 Customer Service 1.800.786.3141. Over 200+ of your

favorite brands; Shoes, sandals, boots, clogs, clothing \& more.

Shoebuy - Free Shipping \& Return Shipping

www.shoebuy.com/ - Cached - Similar

View All Women's Shoes Categories ... View All Men's Shoes Categories ... Shoebuy has the largest selection of women's shoes, men's shoes, kids' shoes, ...

BCBGMAXAZRIA: Shop Sale

www.bcbg.com/

Shop Fall! Free Shipping On Regular

Priced Orders with code FALLSHIP

Women's Shoes - NORDSTROM

www.nordstrom.com/

Shop top brands in womens shoes

Free Shipping \& Returns Every Day!

50-90\% Sale Womens Shoes

www.discountwomensdressshoes.com/

Boots Dresses Starting at $\$ 9.99$

Free Shipoina on Orders Over $\$ 100$ 
Figure 2: Page Rank (Position) and Brand Equity

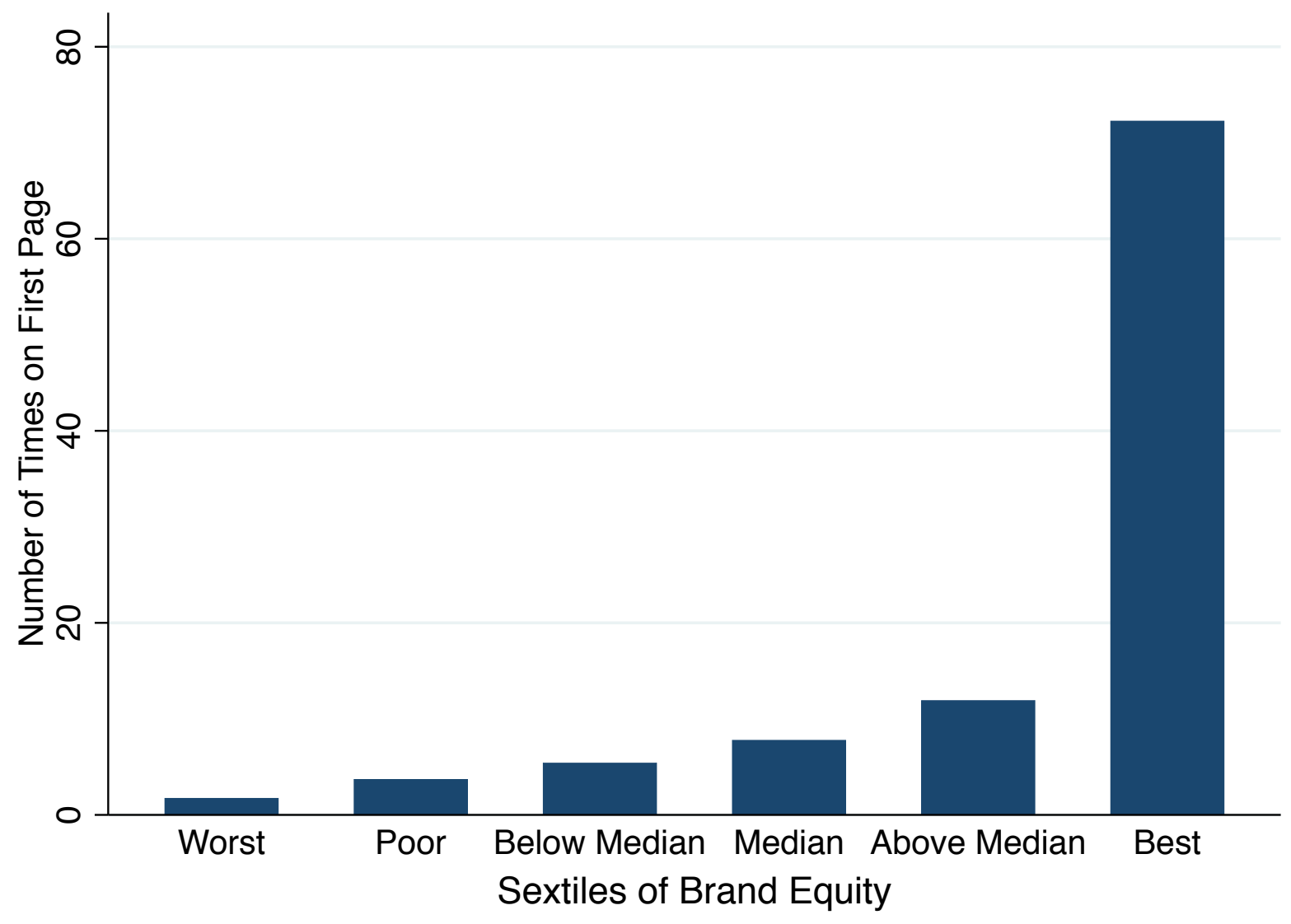


Figure 3: Elasticity of Clicks with Respect to Brand Equity

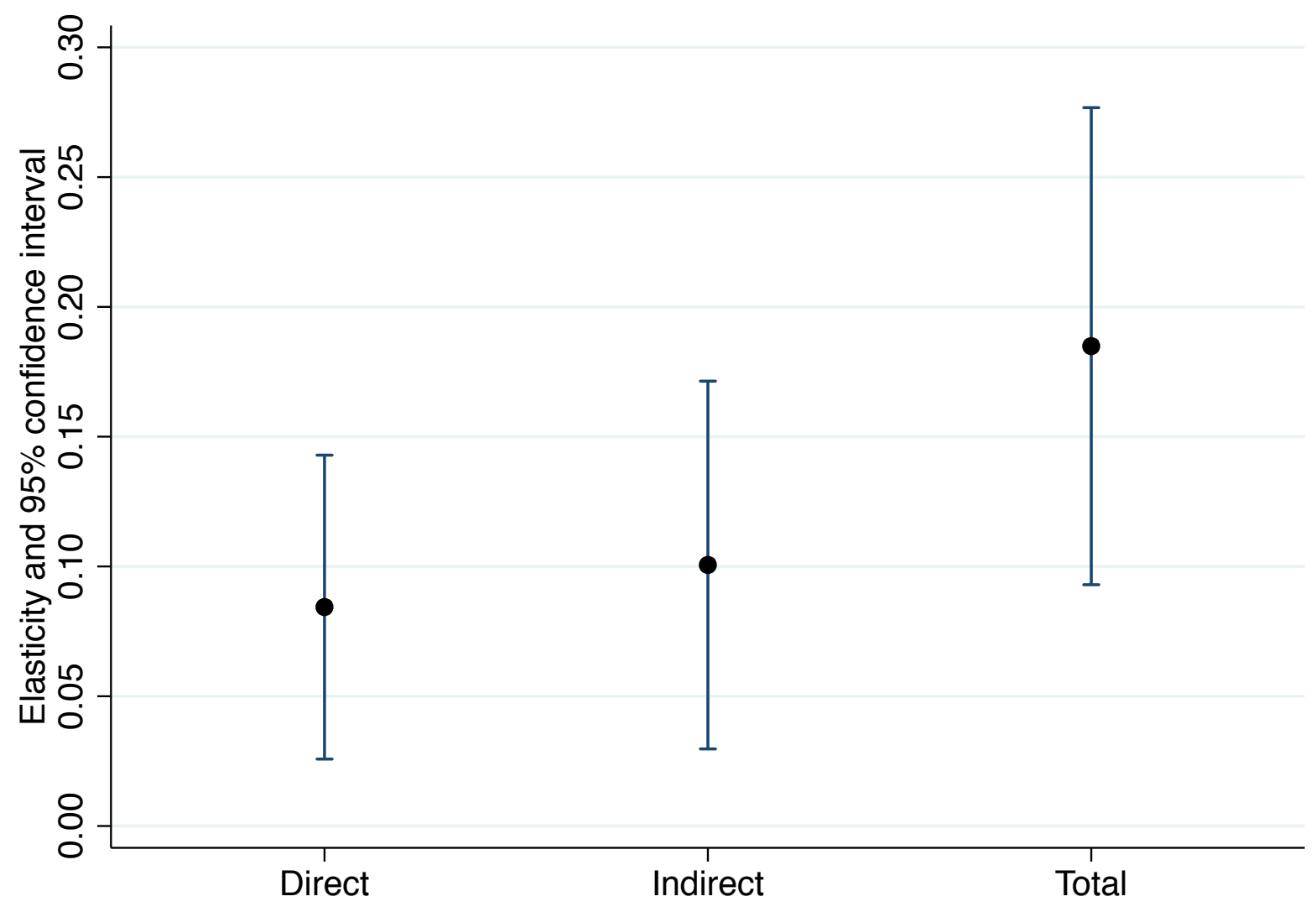


Figure 4: Elasticity of Clicks with Respect to Brand Equity by Income of Searcher

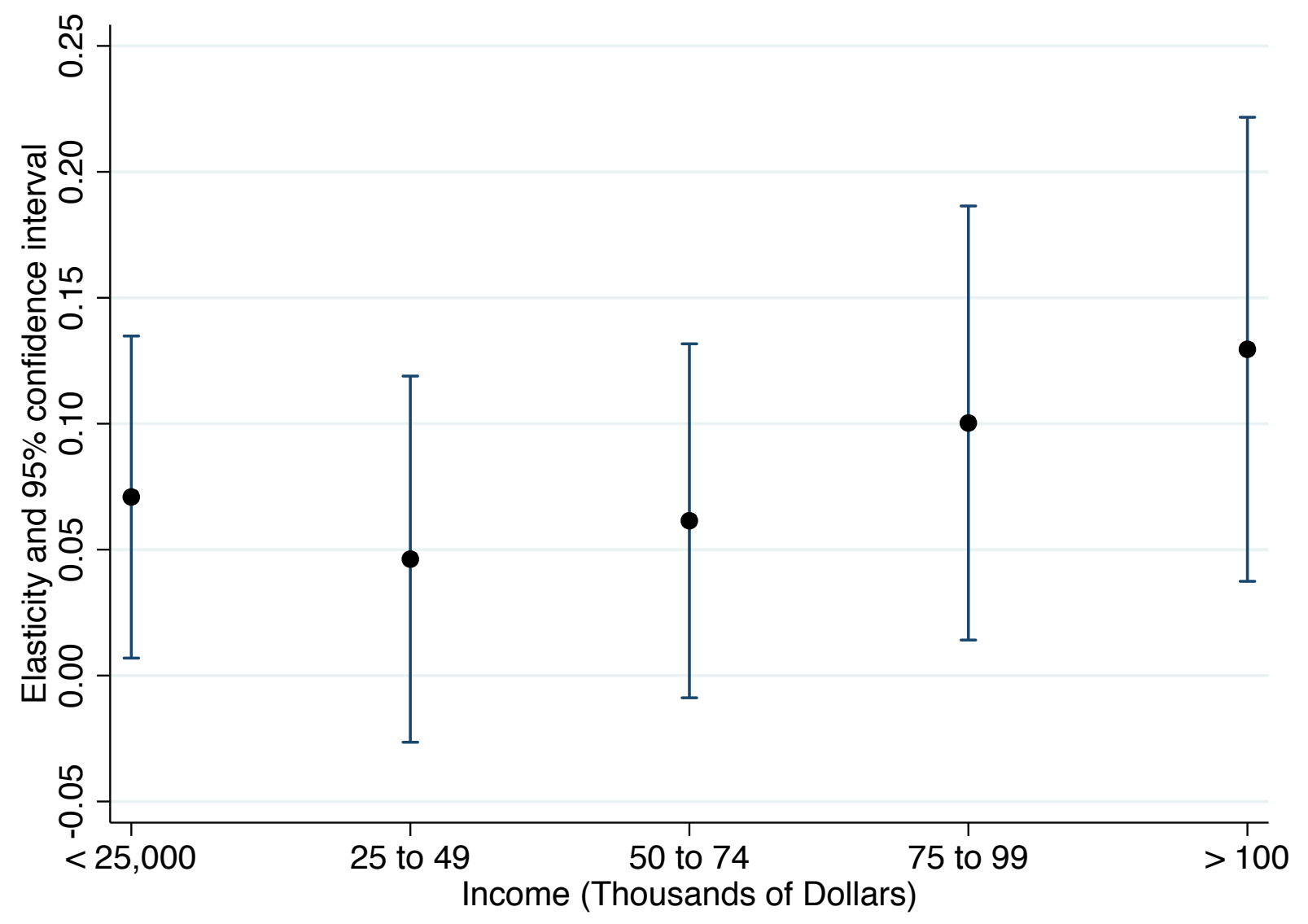


Table 1: Descriptive Statistics $(N=40,117)$

\begin{tabular}{|c|c|c|c|c|}
\hline Variable & Mean & Std. Dev. & Min & Max \\
\hline \multicolumn{5}{|l|}{ Google Related Data } \\
\hline Organic clicks & 2,039 & 10,809 & 0 & 752,296 \\
\hline Brand Equity (thousands) & 3,412 & 5,746 & 0 & 18,000 \\
\hline Rank & 20.480 & 17.564 & 1 & 52 \\
\hline Rank not observed & 0.114 & 0.317 & 0 & 1 \\
\hline Sponsored Link on first page & 0.311 & 0.463 & 0 & 1 \\
\hline \multicolumn{5}{|l|}{ Bing Related Data } \\
\hline Rank & 35.895 & 20.652 & 1 & 52 \\
\hline Rank not observed & 0.574 & 0.494 & 0 & 1 \\
\hline Sponsored Link on first page & 0.064 & 0.244 & 0 & 1 \\
\hline \multicolumn{5}{|l|}{ Alexa Related Data } \\
\hline Sites Linking In (thousands) & 186 & 395 & 0 & 1,183 \\
\hline \multicolumn{5}{|l|}{ Demographics } \\
\hline Age $18-24$ & 0.097 & 0.166 & 0 & 1 \\
\hline Age 25-34 & 0.176 & 0.220 & 0 & 1 \\
\hline Age $35-44$ & 0.213 & 0.235 & 0 & 1 \\
\hline Age 45-54 & 0.252 & 0.249 & 0 & 1 \\
\hline Age $55-64$ & 0.157 & 0.219 & 0 & 1 \\
\hline Age $65+$ & 0.105 & 0.186 & 0 & 1 \\
\hline Income $<25 \mathrm{k}$ & 0.168 & 0.218 & 0 & 1 \\
\hline Income $25-50 \mathrm{k}$ & 0.217 & 0.232 & 0 & 1 \\
\hline Income $50-75 \mathrm{k}$ & 0.211 & 0.231 & 0 & 1 \\
\hline Income $75-100 \mathrm{k}$ & 0.153 & 0.207 & 0 & 1 \\
\hline Income $>100 \mathrm{k}$ & 0.251 & 0.271 & 0 & 1 \\
\hline Home & 0.792 & 0.278 & 0 & 1 \\
\hline Children & 0.649 & 0.291 & 0 & 1 \\
\hline \multicolumn{5}{|l|}{ Search Term Characteristics } \\
\hline Branded Search Term & 0.141 & 0.348 & 0 & 1 \\
\hline Number of words & 2.367 & 1.025 & 1 & 12 \\
\hline \multicolumn{5}{|l|}{ Retailer Characteristics } \\
\hline Social network presence & 0.944 & 0.230 & 0 & 1 \\
\hline Site age & 13.710 & 2.827 & 2 & 24 \\
\hline Web only retailer & 0.323 & 0.468 & 0 & 1 \\
\hline \multicolumn{5}{|l|}{ Retail Segment } \\
\hline Apparel/accessories & 0.217 & 0.412 & 0 & 1 \\
\hline Automotive parts/accessories & 0.006 & 0.075 & 0 & 1 \\
\hline Books/music/video & 0.020 & 0.139 & 0 & 1 \\
\hline Computers/electronics & 0.128 & 0.334 & 0 & 1 \\
\hline Flowers/gifts & 0.005 & 0.070 & 0 & 1 \\
\hline Food/drug & 0.012 & 0.110 & 0 & 1 \\
\hline Hardware/home improvement & 0.042 & 0.201 & 0 & 1 \\
\hline Health/beauty & 0.022 & 0.148 & 0 & 1 \\
\hline Housewares/home furnishings & 0.032 & 0.176 & 0 & 1 \\
\hline Jewelry & 0.005 & 0.074 & 0 & 1 \\
\hline Mass merchant & 0.363 & 0.481 & 0 & 1 \\
\hline Office supplies & 0.019 & 0.136 & 0 & 1 \\
\hline Specialty/non-apparel & 0.054 & 0.225 & 0 & 1 \\
\hline Sporting Goods & 0.047 & 0.211 & 0 & 1 \\
\hline Toys/hobbies & 0.028 & 0.166 & 0 & 1 \\
\hline
\end{tabular}


Table 2: Main Results

\begin{tabular}{lc}
\hline \hline Dependent variable: log of organic clicks on Google \\
\hline & \\
$\ln ($ Rank) & $-1.347(0.252)^{* * *}$ \\
Rank not observed & $-2.335(0.616)^{* * *}$ \\
Sponsored Link on first page & $0.317(0.150)^{* *}$ \\
ln(Brand Equity) & $0.084(0.030)^{* * *}$ \\
Age 18-24 & $-0.109(0.124)$ \\
Age 25-34 & $0.088(0.108)$ \\
Age 35-44 & $0.141(0.103)$ \\
Age 55-64 & $0.223(0.107)^{* *}$ \\
Age 65+ & $0.181(0.132)$ \\
Income $<25 \mathrm{k}$ & $-0.708(0.107)^{* * *}$ \\
Income 25-50k & $-0.211(0.100)^{* *}$ \\
Income 75-100k & $0.337(0.111)^{* * *}$ \\
Income $>100 \mathrm{k}$ & $0.773(0.12)^{* * *}$ \\
Home & $-1.451(0.149)^{* * *}$ \\
Children & $-0.191(0.074)^{* *}$ \\
Branded search term & $0.101(0.057)^{* *}$ \\
Number of words & $-0.138(0.035)^{* * *}$ \\
Social network presence & $0.056(0.144)$ \\
Site age & $0.012(0.009)$ \\
Web only retailer & $0.127(0.053)^{* *}$ \\
& \\
Inverse Mills ratio & $0.851(0.286)^{* * *}$ \\
& \\
Observations & 40,117 \\
Censored & 5,681 \\
Uncensored & 34,436 \\
Selection & Yes \\
Endogeneity & Yes \\
& \\
\hline
\end{tabular}

Notes: * significant at $10 \%$; $* *$ significant at $5 \%$;

$* * *$ significant at $1 \%$. Robust standard errors in parentheses. All specifications include a constant and retail segment fixed effects. 
Table 3: Robustness: Alternative Measures of Brand

\begin{tabular}{|c|c|c|c|}
\hline & \multicolumn{3}{|c|}{ Dependent variable: log of organic clicks on Google } \\
\hline & (1) Lagged Brand & (2) Bing & (3) Brand Equity on Alexa \\
\hline $\ln ($ Rank $)$ & $-1.463(0.263)^{* * *}$ & $-1.162(0.227)^{* * *}$ & $-1.282(0.237)^{* * *}$ \\
\hline Rank not observed & $-2.569(0.655)^{* * *}$ & $-1.910(0.554)^{* * *}$ & $-2.154(0.594)^{* * *}$ \\
\hline Sponsored Link on first page & $0.422(0.165)^{* *}$ & $0.245(0.138)^{*}$ & $0.404(0.160)^{* *}$ \\
\hline $\ln$ (Brand Equity) & $0.091(0.029)^{* * *}$ & $0.035(0.017)^{* *}$ & $0.124(0.032)^{* * *}$ \\
\hline Age 18-24 & $-0.068(0.131)$ & $-0.151(0.116)$ & $-0.116(0.121)$ \\
\hline Age $25-34$ & $0.117(0.114)$ & $0.066(0.102)$ & $0.084(0.105)$ \\
\hline Age 35-44 & $0.162(0.107)$ & $0.128(0.097)$ & $0.138(0.101)$ \\
\hline Age 55-64 & $0.209(0.112)^{*}$ & $0.231(0.101)^{* *}$ & $0.229(0.106)^{* *}$ \\
\hline Age $65+$ & $0.189(0.140)$ & $0.180(0.124)$ & $0.179(0.131)$ \\
\hline Income $<25 \mathrm{k}$ & $-0.728(0.113)^{* * *}$ & $-0.674(0.099)^{* * *}$ & $-0.689(0.104)^{* * *}$ \\
\hline Income $25-50 \mathrm{k}$ & $-0.231(0.105)^{* *}$ & $-0.199(0.093)^{* *}$ & $-0.205(0.098) * *$ \\
\hline Income $75-100 \mathrm{k}$ & $0.339(0.116)^{* * *}$ & $0.331(0.105)^{* * *}$ & $0.342(0.110)^{* * *}$ \\
\hline Income $>100 \mathrm{k}$ & $0.805(0.130)^{* * *}$ & $0.721(0.114)^{* * *}$ & $0.757(0.119)^{* * *}$ \\
\hline Home & $-1.529(0.159)^{* * *}$ & $-1.363(0.138)^{* * *}$ & $-1.432(0.147)^{* * *}$ \\
\hline Children & $-0.187(0.077)^{* *}$ & $-0.206(0.069)^{* * *}$ & $-0.201(0.072)^{* * *}$ \\
\hline Branded search term & $0.114(0.060)^{*}$ & $0.093(0.054)^{*}$ & $0.077(0.057)$ \\
\hline Number of words & $-0.151(0.037)^{* * *}$ & $-0.115(0.032)^{* * *}$ & $-0.133(0.034)^{* * *}$ \\
\hline Social network presence & $0.132(0.155)$ & $0.030(0.135)$ & $-0.042(0.141)$ \\
\hline Site age & $0.015(0.009)$ & $0.015(0.009)^{*}$ & $0.000(0.009)$ \\
\hline Web only retailer & $0.143(0.056)^{* *}$ & $0.117(0.050)^{* *}$ & $-0.041(0.054)$ \\
\hline Inverse Mills ratio & $1.011(0.308)^{* * *}$ & $0.626(0.251)^{* *}$ & $0.817(0.278)^{* * *}$ \\
\hline Observations & 40,117 & 40,117 & 40,117 \\
\hline Censored & 5,681 & 5,681 & 5,681 \\
\hline Uncensored & 34,436 & 34,436 & 34,436 \\
\hline Selection & Yes & Yes & Yes \\
\hline Endogeneity & Yes & Yes & Yes \\
\hline
\end{tabular}

Notes: * significant at $10 \% ; * *$ significant at $5 \% ; * * *$ significant at $1 \%$. Robust standard errors in parentheses. All specifications include a constant and retail segment fixed effects. 
Table 4: Robustness: Alternative Censoring Models

\begin{tabular}{lcc}
\hline \hline & \multicolumn{2}{c}{ Dependent variable: log of organic clicks on Google } \\
\cline { 2 - 3 } & Tobit with IV & Tobit \\
\hline & & \\
ln(Rank) & $-2.887(0.118)^{* * *}$ & $-2.800(0.040)^{* * *}$ \\
Rank not observed & $-5.544(0.788)^{* * *}$ & $-4.199(0.101)^{* * *}$ \\
Sponsored Link on first page & $0.381(0.29)$ & $-1.021(0.064)^{* * *}$ \\
ln(Brand Equity) & $0.232(0.019)^{* * *}$ & $0.275(0.017)^{* * *}$ \\
Age 18-24 & $0.775(0.190)^{* * *}$ & $0.701(0.190)^{* * *}$ \\
Age 25-34 & $0.335(0.156)^{* *}$ & $0.332(0.156)^{* *}$ \\
Age 35-44 & $-0.041(0.149)$ & $-0.001(0.149)$ \\
Age 55-64 & $-0.106(0.159)$ & $-0.108(0.159)$ \\
Age 65+ & $-0.498(0.186)^{* * *}$ & $-0.456(0.186)^{* *}$ \\
Income $<25 \mathrm{k}$ & $-0.606(0.171)^{* * * *}$ & $-0.620(0.171)^{* * *}$ \\
Income 25-50k & $-0.319(0.157)^{* *}$ & $-0.281(0.158)^{*}$ \\
Income 75-100k & $0.197(0.168)$ & $0.200(0.168)$ \\
Income $>100 \mathrm{k}$ & $0.765(0.143)^{* * *}$ & $0.750(0.143)^{* * *}$ \\
Home & $-1.397(0.110)^{* * *}$ & $-1.314(0.110)^{* * *}$ \\
Children & $0.166(0.104)$ & $0.115(0.104)$ \\
Branded search term & $0.041(0.085)$ & $0.168(0.083)^{* *}$ \\
Number of words & $-0.202(0.029)^{* * *}$ & $-0.175(0.028)^{* * *}$ \\
Social network presence & $0.232(0.173)$ & $0.185(0.169)$ \\
Site age & $0.038(0.013)^{* * *}$ & $0.034(0.012)^{* * *}$ \\
Web only retailer & $0.457(0.070)^{* * *}$ & $0.518(0.069)^{* * *}$ \\
& & \\
Observations & 40,117 & 40,117 \\
Censored & 5,681 & 5,681 \\
Uncensored & 34,436 & 34,436 \\
Selection & No & Yes \\
Endogeneity & & No \\
& & \\
\hline
\end{tabular}

Notes: $*$ significant at $10 \% ; * *$ significant at $5 \% ; * * *$ significant at $1 \%$. Robust standard errors in parentheses. All specifications include a constant and retail segment fixed effects. 
Table 5: Unpooled Results by Income

\begin{tabular}{|c|c|c|c|c|c|}
\hline & \multicolumn{5}{|c|}{ Dependent variable: log of organic clicks on Google (for income group) } \\
\hline & Income $<25 \mathrm{k}$ & Income $25-50 \mathrm{k}$ & Income $50-75 \mathrm{k}$ & Income $75-100 \mathrm{k}$ & Income $>100 \mathrm{k}$ \\
\hline $\ln ($ Rank $)$ & $-1.143(0.212) * * *$ & $-0.963(0.243) * * *$ & $-1.235(0.238) * * *$ & $-1.426(0.222) * * *$ & $-1.619(0.244) * * *$ \\
\hline Rank not observed & $-1.887(0.511)^{* * *}$ & $-1.166(0.563)^{* *}$ & $-1.818(0.531)^{* * *}$ & $-1.877(0.527)^{* * *}$ & $-2.526(0.567) * * *$ \\
\hline Sponsored Link on first page & $0.309(0.174)^{*}$ & $0.257(0.187)$ & $0.283(0.195)$ & $0.397(0.210)^{*}$ & $0.589(0.245)^{* *}$ \\
\hline $\ln ($ Brand Equity) & $0.071(0.033)^{* *}$ & $0.046(0.037)$ & $0.061(0.036)^{*}$ & $0.100(0.044) * *$ & $0.130(0.047)^{* * *}$ \\
\hline Age $35-44$ & $0.305(0.149)^{* *}$ & $0.079(0.144)$ & $0.268(0.165)$ & $0.007(0.206)$ & $-0.026(0.185)$ \\
\hline Age 55-64 & $0.057(0.158)$ & $0.175(0.153)$ & $0.306(0.172)^{*}$ & $-0.011(0.203)$ & $0.115(0.202)$ \\
\hline Age $65+$ & $0.383(0.183)^{* *}$ & $0.083(0.183)$ & $0.174(0.194)$ & $-0.471(0.237)^{* *}$ & $0.013(0.221)$ \\
\hline Home & $-0.030(0.189)$ & $-0.460(0.215)^{* *}$ & $-0.979(0.216)^{* * *}$ & $-0.729(0.259) * * *$ & $-1.337(0.267)^{* * *}$ \\
\hline Children & $-0.182(0.105)^{*}$ & $-0.221(0.107)^{* *}$ & $-0.220(0.120)^{*}$ & $-0.542(0.139) * * *$ & $-0.414(0.143) * * *$ \\
\hline Site age & $0.010(0.010)$ & $0.013(0.010)$ & $0.011(0.012)$ & $0.005(0.013)$ & $0.012(0.014)$ \\
\hline Web only retailer & $0.107(0.064)^{*}$ & $0.079(0.065)$ & $0.104(0.071)$ & $0.224(0.084)^{* * *}$ & $0.291(0.096)^{* * *}$ \\
\hline Inverse Mills ratio & $0.820(0.290)^{* * *}$ & $0.456(0.332)$ & $0.730(0.325)^{* *}$ & $0.848(0.364)^{* *}$ & $1.323(0.423)^{* * *}$ \\
\hline Observations & 40,117 & 40,117 & 40,117 & 40,117 & 40,117 \\
\hline Censored & 4,558 & 4,602 & 4,409 & 3,800 & 3,773 \\
\hline Uncensored & 35,559 & 35,515 & 35,708 & 36,317 & 36,344 \\
\hline Selection & Yes & Yes & Yes & Yes & Yes \\
\hline Endogeneity & Yes & Yes & Yes & Yes & Yes \\
\hline
\end{tabular}

Notes: ${ }^{*}$ significant at $10 \% ; * *$ significant at 5\%; $* * *$ significant at $1 \%$. Robust standard errors in parentheses. All specifications include a constant and retail segment fixed effects. 